\title{
The Case of "CG": Balancing Supportive and Insight-Oriented, Psychodynamic Therapy with a Client Undergoing Intense Life Stresses
}

\author{
KAREN RIGGS SKEAN ${ }^{\mathrm{a}, \mathrm{b}}$ \\ ${ }^{a}$ Graduate School of Applied and Professional Psychology, Rutgers - The State University of New Jersey \\ ${ }^{\mathrm{b}}$ Correspondence concerning this article should be addressed to Karen Riggs Skean, Rutgers University, Graduate \\ School of Applied and Professional Psychology, 152 Frelinghuysen Road, Piscataway, NJ 08854. \\ Email: kskean@aol.com
}

\begin{abstract}
"CG," a 28-year-old graduate student, initially presented with complaints of depression, in response to social isolation and academic problems that had resulted in being placed on probation. Based on a history with non-nurturing parents who either neglected or physically abused him, CG had developed as an independent, interpersonally cut-off individual with a suspicious, paranoid view of the world, making initial therapeutic access to him quite challenging. Not surprisingly, in spite of a very problematic personal history, he had never before sought any kind of therapy, stating at intake that he was trying it as a "last resort." As the therapist, I employed a broadly defined, object-relations-focused, psychodynamic framework, with a particular emphasis upon balancing supportive versus insight-oriented modes of therapy. This balance turned out to be a key factor in developing an effective therapeutic relationship with this client and in helping him to move towards a more engaged and connected bond with his social world.
\end{abstract}

Key words: psychodynamic therapy; supportive vs. insight-oriented therapy; intense life stress

\section{CASE CONTEXT AND METHOD}

\section{A. The Rationale for Selecting This Particular Client for Study.}

"CG," a 28-year-old graduate student, initially came to see me in a small group, private practice in the community in June. He complained of depression, in response to a previous academic year of great stress, including social isolation and academic problems that had resulted in probation. CG exemplifies a client with a difficult and challenging initial presentation, including a number of indicators obviating against the establishment of a strong therapeutic alliance. However, CG nonetheless was able to engage in and benefit considerably from treatment, even though, at least by psychodynamic standards, the therapy was relatively shortterm (11 months). Also, the shorter time frame allows us to look at a beginning, a middle, and an end to the treatment without an unmanageably large amount of data, helping to facilitate a clearer 
The Case of "CG": Balancing Supportive and Insight-Oriented,

Psychodynamic Therapy with a Client Undergoing Intense Life Stresses

K.R. Skean

Pragmatic Case Studies in Psychotherapy, http://pcsp.libraries.rutgers.edu

Volume 1, Module 3, Article 1, pp. 1-18, 10-21-05 [copyright by author]

focus on specific therapeutic moments and on stages of the treatment. Finally, this case allows for a close look at how to balance support-oriented versus insight-oriented modes of therapist interaction in psychodynamic therapy.

\section{B. The Methodological Strategies Employed for Enhancing the Rigor of The Study}

CG was seen in ordinary clinical practice without, at the time of treatment, plans for publication. It would, of course, have been ideal if he had been audiotaped or videotaped, or in some other way independently documented to create a more objective database. On the other hand, given the guarded and suspicious initial presentation of the client, this might not have been a realistic option even if it had been considered at the time. In any event, there were some sources of monitoring outside my role as the therapist and outside the client dyad. Being somewhat early in my clinical career, I was in ongoing supervision at the time and presented the client to two different supervisors, particularly in the early phases of treatment when my own subjective (countertransferential) reaction to the client was more troublesome and the establishment of the therapeutic alliance was in doubt. Both of these supervisors later read the case narrative and found it consistent with what had been discussed.

\section{The Clinical Setting in Which the Case Took Place}

The setting was a small group, private practice in the community. Fees were established on a sliding scale.

\section{Sources of Data Available Concerning the Client}

Little data were available outside the referral and therapy process described below. There was an outside consultation with a psychiatrist mid-way through treatment regarding medication. The client had not previously been in treatment, so no prior reports were available.

\section{E. Confidentiality}

Confidentiality was maintained by including no information in the text by which the client could be identified. All information is de-identified, with anything that might risk exposure further disguised, while remaining as true to the process and dynamics of the case as possible. The current whereabouts of the client are unknown, so it was not possible to seek his permission for publication.

\section{THE CLIENT}

CG was a graduate student in a masters program in a business discipline. Tall and thin, his prematurely gray hair and stiff manner made him appear considerably older than his 28 years. He had graduated from the state university in his home state, which was some distance away, worked for a major corporation for four years, then left his job to return to school for a master's 
The Case of "CG": Balancing Supportive and Insight-Oriented,

Psychodynamic Therapy with a Client Undergoing Intense Life Stresses

K.R. Skean

Pragmatic Case Studies in Psychotherapy, http://pcsp.libraries.rutgers.edu

Volume 1, Module 3, Article 1, pp. 1-18, 10-21-05 [copyright by author]

degree. He was single, had never dated, and at the time of intake, stated that he had made no friends in the year he had been at the university and lacked any support system. CG's initial complaint was depression, which he attributed to having undergone a year of continuous stress. He had never before sought any kind of therapy, stating he was trying it as a "last resort."

\section{GUIDING CONCEPTION WITH RESEARCH AND CLINICAL EXPERIENCE SUPPORT}

I approached this case employing a broadly defined, object-relations-focused, psychodynamic framework. The following sections elaborate on basic themes of this guiding conception and will be later discussed again in relation to the formulation, course of therapy and evaluation of treatment.

\section{A. The Use of the Therapeutic Relationship}

This psychodynamic framework attends to a particular kind of process in the therapeutic encounter and believes that an important way of understanding a human being is in the context of the unfolding relationship with the therapist (Strupp \& Binder, 1984; Spence, 1982). This attending to the relationship is critical both for assessment and intervention. It is through the relationship that the client brings his or her interpersonal world into the treatment room and allows the therapist to experience aspects of the client's structuring of reality. The supportive, empathic aspects of the relationship "hold" the person in the treatment, providing experiences that may be new to the client, while the more interpretive aspects use the relationship to encourage reflection on the way the client has structured and made meaning of the world.

\section{B. Defenses and Transference}

Each person selectively shapes and makes sense of his or her experience, accepting and integrating some of it, and hiding other parts to avoid painful feelings. Much of this occurs outside of awareness (is "unconscious"). The shaping is guided and reinforced by three dynamic elements: unexamined assumptions, unconscious conflicts, and previously developed templates ("transferences") for personal relationships. Problems arise when these dynamic elements limit a person's ability to function effectively, impairing capacities to love and to work productively. Paul Wachtel's (1997) concept of "cyclical psychodynamics" views a negative template as stimulating client behaviors that elicit the very negative behaviors from others that the client expects, thus both confirming the negative template and failing to let in experiences that might disconfirm it.

Through the examination of client transference and therapist countertransference, through the attention to the operation of characteristic defense mechanisms, and by having an interpersonal experience in the therapy that differs from others he or she may have known, the client is encouraged to expand his or her understanding of self in a way that provides more options and choices (Freud, 1966; Gill, 1982; McWilliams, 2004, 1999; Vaillant, 1993, 1977). 
The Case of "CG": Balancing Supportive and Insight-Oriented,

Psychodynamic Therapy with a Client Undergoing Intense Life Stresses

K.R. Skean

Pragmatic Case Studies in Psychotherapy, http://pcsp.libraries.rutgers.edu

Volume 1, Module 3, Article 1, pp. 1-18, 10-21-05 [copyright by author]

An assessment of the unique way in which the individual structures his or her world in terms of the configuration of defenses, the experience of the self and other, and the ways these play out moment to moment in the therapeutic relationship helps to form an evolving guide to intervention (McWilliams, 1994).

Psychodynamic assessment, like assessment in any model, takes numerous factors into account. Among these factors are: constitutional, biological, temperamental givens; relationships with self and others (both internal and external); inferred defensive/adaptational processes we might consider "personality structure"; the themes and identifications around which the client has organized his or her experience; and in relation to all this, how well this configuration is working for the client. The more complete this formulation can be at the beginning, the better, but it is also subject to change and evolution as therapy progresses. Intervention is in many ways begun from the start, with priority given to development of a trusting, therapeutic working relationship, and often, as was true in this case, relevant assessment information emerges over the course of the therapy and becomes available as the therapy relationship develops.

\section{Importance of the Life History}

The life history, not just "what happened," but the way in which the client internalized and interpreted the events and the relationships of that history is a major focus during the assessment phase and provides a data base from which many later interventions are drawn.

\section{Support-Oriented Strategies and Insight-Oriented Strategies}

Numerous authors (Luborsky, 1985; McWilliams, 1994; Pine, 1984; Josephs, 1995) have contrasted two different, though not opposed, dimensions of analytic work: (a) the supportive, and (b) the "expressive," or "insight-oriented." Pine describes the supportive function of therapy in terms of a model of good parenting: what we are and do for our clients, as when we provide a safe environment or confirm the client's subjective experience. This is much like Winnicott's (1965) "holding environment." Supportive strategies empathically validate the client's personhood, life struggles, and suffering.

Psychoanalysis proper has placed greater emphasis on insight, on "making the unconscious conscious" (Freud, 1966), relying upon interpretations made when a conflict is affectively felt under conditions of relative lack of need satisfaction. Insight-oriented strategies challenge defenses and maladaptive transference schemas with alternative and more adaptive interpersonal experiences, both within the therapeutic relationship itself and in the client's outside life. Pine stresses the need for a balance between these two dimensions, a balance struck by careful attention to the client's ability to use any given intervention. This case presents an example of the need for such a balance.

In terms of my prior experience with similar cases, at the time of the treatment, I had had training and supervision in long-term, psychodynamically-oriented psychotherapy as well as in- 
The Case of "CG": Balancing Supportive and Insight-Oriented,

Psychodynamic Therapy with a Client Undergoing Intense Life Stresses

K.R. Skean

Pragmatic Case Studies in Psychotherapy, http://pcsp.libraries.rutgers.edu

Volume 1, Module 3, Article 1, pp. 1-18, 10-21-05 [copyright by author]

depth, specific training in short-term dynamic psychotherapy, with several years of experience using this model with a university population.

\section{ASSESSMENT OF THE CLIENT'S PROBLEMS, GOALS, STRENGTHS, AND HISTORY}

CG came to our group practice in early summer complaining of depression. This was a result, in his view, of a year of continuous stress during his first year in graduate school. He was engaged in battles on every front - from his academic department to numerous other branches of the university. Problems with his department were particularly pressing. He did very poorly in two undergraduate statistics courses he was required to take as a part of his program. Unaware that these would count toward his graduate GPA, he was surprised to find himself placed on probation and in danger of being dismissed from the program. His vigorous attempts to straighten this out had been thus far unsuccessful, and he felt that his record had been permanently damaged. He had begun to feel that his department wanted to get rid of him, that his professors were avoiding him and that he was unjustly overlooked for assistantship positions for which he felt more qualified than the students selected over him.

Problems were not limited to his academic department: housing, university administration, the financial aid office, and the registrar had all received numerous complaints and petitions from CG. Indeed, by the time he got to the counseling center, it appeared that CG had blazed a litigious trail through much of the university.

Although he described his problem as "depression," CG denied feeling sad, though he acknowledged that he was frustrated and "demoralized." Symptoms were expressed in objectified terms: "My time management skills are going downhill." Concentration and memory were impaired, and he was experiencing a constant sense of fatigue, though he denied significant disturbances of sleeping or eating. He was oriented and denied suicidal or homicidal ideation.

\section{Brief Personal History Relevant to Assessment}

CG was born and raised in a suburb of a large city. The third of three children, his sister was three years older and his brother five years older than he. His father worked as a supervisor for a manufacturing plant. His mother, a housewife, had never worked outside the home.

Despite CG's family's presentation to the world of a "normal, middle-class family," in fact his family life was chaotic and violent. His parents fought constantly and bitterly, and the children were physically abused by both parents, especially by their father. CG was the only "fighter" and became the prime target of the abuse. His father either ignored the children, as if they were "pieces of furniture" (and indeed did not say hello to them if he passed them in the street), or else physically abused them. He played sadistic games which invited no-win conflicts, e.g., turning down the heat unbearably low, then beating up any child who tried to turn it up. CG seemed a particular scapegoat of his father, who stopped talking to him at the age of eight. CG's 
The Case of "CG": Balancing Supportive and Insight-Oriented,

Psychodynamic Therapy with a Client Undergoing Intense Life Stresses

K.R. Skean

Pragmatic Case Studies in Psychotherapy, http://pcsp.libraries.rutgers.edu

Volume 1, Module 3, Article 1, pp. 1-18, 10-21-05 [copyright by author]

anger and need to distance from his father was so great that he referred to him only as "my mother's husband."

CG saw his mother as a weak and passive woman, uneducated, having no job skills, and too frightened to get out of a bad marriage. She not only failed to protect him from his father's abuse, but also physically abused him herself until his early adolescence when he became stronger than she. His parents finally did divorce when he was in college. His only contact with his father during this time occurred when his father appeared suddenly at his dorm during the middle of finals and announced that $\mathrm{CG}$ would no longer be covered under his medical insurance (this was by way of informing him of the divorce) and left. He has since that time maintained no relationship with his father.

CG and his two siblings all did well in school. These academic accomplishments went unrecognized by their father, but were valued by their mother. This seemed to be the one area where CG could get some validation, both outside and inside the family. He had a few same-sex friends growing up, but this seemed to involve mainly sharing of activities: he told none of these friends about his family problems. CG was always tall for his age, underweight throughout adolescence, and always experienced himself as awkward, unattractive and unathletic. He also had chronic eye problems, a tendency to form premature cataracts, and had undergone several operations, beginning at age twelve. Although at least these health needs were provided for, solely through his mother's efforts, he was not encouraged to talk about or work through any emotional reactions he had to these frightening and invasive procedures.

From the age of 13, CG earned all his own money, as he never felt he could ask his parents for anything, and paid his own way through college. His self-image was of himself as a fighter, a survivor, someone who could take care of himself by himself. Therapy was seen as a challenge to this view of self.

\section{Presentation at the Beginning of Therapy}

An astute physician at the university health center who was monitoring his eye condition referred him to our group practice, though it was several months until he followed through and made an appointment, describing it as a "last resort," and clearly viewing the seeking of help as a defeat and a shame-filled experience.

At the time of the initial assessment phase, CG's style of dealing with the world had a marked paranoid flavor. Suspiciousness and mistrust pervaded his world and were reflected in the transference as well. He clearly expected from his university-affiliated therapist the same mistreatment he felt he had received during all his other interactions with the university. He was guarded about revealing anything of himself lest it be used against him. He was unable to see any way in which he might have participated in his difficulties. He was tense, easily slighted, and ready to counterattack. He appeared cold and humorless, constantly struggling for objective, rational control over the situation. 
The Case of "CG": Balancing Supportive and Insight-Oriented,

Psychodynamic Therapy with a Client Undergoing Intense Life Stresses

K.R. Skean

Pragmatic Case Studies in Psychotherapy, http://pcsp.libraries.rutgers.edu

Volume 1, Module 3, Article 1, pp. 1-18, 10-21-05 [copyright by author]

\section{Diagnosis and Strengths}

I think it important to note that the above observations were not of CG's highest level of functioning, but quite possibly of his lowest. The externalizing defenses emerged under conditions of what were for him near-intolerable stresses and related threats to his sense of self worth, which was based upon his previous academic and vocational accomplishments. This case highlights the ongoing process of assessment. The client did not appear the same in session one

as he did in session six. The diagnosis, on a descriptive/observational level, would have shifted (from paranoid personality to more obsessive-compulsive personality). His level of suspiciousness decreased markedly over the course of the therapy.

In DSM terms, the differential on Axis I would be between an adjustment disorder and a more longstanding depression. Clearly, given the level of stressors and his degree of being overwhelmed by them when he presented for treatment, criteria for an Adjustment Disorder with Depressed Mood would have been met. Whether he would have met criteria for Dysthymia is trickier, since the client resisted seeing himself as "sad," or "depressed" in mood, though one could argue that there were many indicators of a diminishment of pleasure and self-esteem so longstanding as to have become in many ways ego-syntonic. At a later point in treatment, though only for a limited time, CG would have met criteria for a Major Depressive Episode. On Axis II, CG met criteria for an Obsessive-Compulsive Personality Disorder. At the beginning of treatment, he could potentially be seen as having met criteria for a Paranoid Personality Disorder, though the question of whether that was more situational rather than longstanding argued for this being more a potential rather than a fixed diagnosis.

The client also had several strengths. He had a history of functioning independently, maintained an image of self as a fighter and survivor that had indeed helped him survive a seriously depriving early environment. He was intelligent and able to diligently apply that intelligence to specific tasks.

\section{FORMULATION AND TREATMENT PLAN}

\section{Formulation}

For CG, the interpersonal world had always been unreliable, alien and hostile. A primary means of coping had been to invest in outside accomplishments to build and bolster a fragile sense of self and of self-esteem. This had worked, to a degree. While living a life of few interpersonal satisfactions, he nonetheless achieved a measure of mastery by doing well in school and in work, where he toiled unimaginatively but with obsessive diligence.

The situation he faced at the university could hardly have been a worse combination of forces, given his history and dynamics. He felt deprived of the one thing at which he had felt good and competent - his ability to perform academically - and in a way that seemed unjust. Additionally, a malice-tinged relationship developed with his department chair, who provided a 
The Case of "CG": Balancing Supportive and Insight-Oriented,

Psychodynamic Therapy with a Client Undergoing Intense Life Stresses

K.R. Skean

Pragmatic Case Studies in Psychotherapy, http://pcsp.libraries.rutgers.edu

Volume 1, Module 3, Article 1, pp. 1-18, 10-21-05 [copyright by author]

perfect stand-in for a hated and persecuting father. CG struggled and fought for his rights, but perceived them as only being further eroded. As in his relationship with his father, he experienced his program as a series of no-win conflicts, set up to provide an arena of punishment, abuse and indifference to his suffering. His characteristic defensive style of launching rigid and litigious counterattacks when threatened only made matters worse, creating via a vicious circle the hostile environment he feared (Wachtel, 1997). So CG did not simply fail a few courses, or even a program - he was losing a significant part of what had given his life structure and meaning, and this was a loss too great to be borne. It was a while before he was able to bring this pain into the therapy room, and the externalizing defenses that held this pain at bay also held the therapist at arm's length.

CG suffered from never having had an empathic, attentive, "holding" environment in which to experience and structure his needs and feelings (Winnicott, 1965). Instead, the world of his childhood was, in Guntrip's (1969) terms, both a "frightening emptiness" when it did not respond to his needs, and a "frightening persecutor when it actively and hurtfully impinged" (p. 68). He responded to this by a withdrawal from and a denial of the need for human relationships. This failed to work, not only because of the basic need of human beings to be related to others, but because the "bad objects" - that is, the images of his punishing parents -- had become a part of the structure of his inner world. This inner world thus duplicated the frustrating experience of the outer world of his childhood, and his later projections served to insure that he would to some extent recreate this world wherever he went.

\section{Treatment Plan}

The goals of therapy reflected the two dimensions of analytic work mentioned earlier in the Guiding Conception section. The first goal, and indeed the sine qua non of therapy with this client, was to establish a supportive human relationship, to provide an environment of safety and confirmation of feelings. This support was designed to enable CG to better cope with immediate distressing events, and also to begin work on the second goal of treatment: the insight-oriented exploration of broader issues of how CG participated in the creation of his present difficulties. This second goal had several components for CG: (a) becoming aware of his patterns of behavior that were causing difficulty, (b) understanding that he in part created this world from images carried over from his own life history, and (c) his beginning to try new cognitions and behaviors in order to reverse the negative cycles his old cognitions and behaviors were perpetuating.

A third goal, also supportive, was simply to help CG navigate what for him was a terrible time in his life. Here the aim was for $\mathrm{CG}$ to make it to the other side of a very painful experience (failing out of a program) with a minimum of damage to his fragile sense of self and a maximum of being able to use that experience in a way that opened up rather than closed down the possibility of new learnings about himself. 
The Case of "CG": Balancing Supportive and Insight-Oriented,

Psychodynamic Therapy with a Client Undergoing Intense Life Stresses

K.R. Skean

Pragmatic Case Studies in Psychotherapy, http://pcsp.libraries.rutgers.edu

Volume 1, Module 3, Article 1, pp. 1-18, 10-21-05 [copyright by author]

\section{COURSE OF THERAPY}

\section{Early phase of Therapy: Developing a Relationship (Sessions 1-4)}

At the beginning of therapy, in June of the client's second year in his graduate program, CG was initially quite suspicious and guarded. He gave very little personal information in the first few sessions, refusing to discuss anything about his past and focusing exclusively on the minutiae of wrongs he was suffering at the hands of others. At the end of the first encounter, he was ambivalent about beginning therapy and pressed me very hard on issues of confidentiality. Fearing that what he said in therapy might somehow get out in a way that could hurt him, his intense questions revealed some elaborate fantasies of how this could happen: Who did I have lunch with and what did I talk about? Did I teach classes in the university, ever engage in casual conversation with members of his department? How did he know that I wouldn't share his file with someone in the university? He was concerned that information could somehow get back to his department in a way that would further compromise his status there. It was unclear at that point how truly rejecting, punitive or "out to get him" his department was, as I had access only to CG's experience of the environment, but the distrust he brought with him into the treatment room was likely a product of a vicious circle involving a collision of his defenses and interpersonal templates with the social defenses, organizational structure and administrative policies of his department.

Early sessions were difficult, with CG filling the space with detailed complaints of how others in the environment were making things hard for him. The defenses most evident at that point were denial, projection, and emotional constriction. He was quite ambivalent about therapy, viewing his need for it as weakness, but looking forward to it as his "only human contact of the week." Yet, CG would always leave me with some comment like, "I'm not sure how helpful today's session has been to me." In this first month of treatment, I had trouble finding a way to connect with CG. I felt both locked out of meaningful contact yet punished for my failure to reach him, as he would always manage to let me know I was failing him in some way. In the countertransference, I experienced what I imagined others in his world also experienced - feelings of being sorry to see him come and glad to see him go.

Two kinds of interventions seemed helpful in this period. One was an early working with the negative transference, in which he saw me as yet another arm of the university, as likely incompetent and uncaring if not malicious. The university was already, in the client's negative institutional transference, seen as the abusive parent. Using the many opportunities (questioning of confidentiality, of my ability help him), I reflected that his current experience must make it very difficult for him to trust me, to believe that I would not use his vulnerability to harm him. This approach to him, showing openness to his critical concerns about me, gradually disarmed him, so that by the fifth session he stopped for the most part his criticisms and skepticism about my being able to help him. I suspect that if this had not been worked with early on, it is highly likely that he would have repeated with me his general experience of being misunderstood and abused by yet another university person. 
The Case of "CG": Balancing Supportive and Insight-Oriented,

Psychodynamic Therapy with a Client Undergoing Intense Life Stresses

K.R. Skean

Pragmatic Case Studies in Psychotherapy, http://pcsp.libraries.rutgers.edu

Volume 1, Module 3, Article 1, pp. 1-18, 10-21-05 [copyright by author]

The second kind of intervention which showed evidence of working was to respect the client's defenses, to time what was said in a way that could be heard, and to give him as much control as possible, what Pine (1985) refers to as "acceptance/rejection rights" over any intervention. At the end of our fourth session, following another "I'm not sure how helpful this is" comment, I remarked, "I think you are right. Let me just mention something that might be helpful. Sometimes people tell me something about themselves, about their families, and this helps me to understand them better." This suggested the possibility of letting me in a little further than he had thus far and also gave him control over the timing. He began the following session by saying that he had thought about what I said all week and had decided to give it a try.

\section{CG Reveals His Past (Sessions 5 to6)}

I had, up until this moment (session 5), virtually no knowledge of CG's past, beyond a few reluctantly-given demographics and a sense of a very problematic childhood that I felt in his transferential relationship with me. This session was a turning point in the therapy. CG told, tearfully, with great difficulty, and for the first time to anyone, the story of his very painful and abused childhood. The importance of this lay not in the specific family information, though this did indeed increase my understanding of the dynamics of his current difficulties. Rather, it lay in the beginnings of a process of trust, the thoroughly unaccustomed sharing of pain with another human being.

\section{Pursuing Insight and Trying Out New Behaviors (Session 7 to12)}

The therapy relationship, both in terms of transference and countertransference, shifted markedly after CG's sharing of his troubled past. Against this backdrop, his experience of the university as an abusive environment and of therapy as a potentially abusive one made a great deal of sense. Still ambivalent about revealing himself, he expressed a mixture of relief and fear of vulnerability. He said that because of what he told me, I was able to make some comments that were "insightful." Part of him liked and felt touched by this; part of him was frightened at the way in which this made him feel vulnerable to me. If I held a power to touch him, how could he know that I would use it benevolently? This was to be a continuing feature of our dialectic, a yearning for my understanding, but a fear of the power this understanding might give me. For my part, I felt less fended off and neutralized and began to feel a stronger sense of connection. We were able to begin exploring how his need to protect himself -- by staying with the "abstract" or struggling litigiously for his "rights" -- prevented him from receiving in human relationships the connectedness and support for which he hungered.

Pine talks about "striking while the iron is cold" (1985, p. 153), meaning that with some clients, an interpretation made at a moment when the conflict is affectively alive is not necessarily a time when it can be constructively absorbed and utilized by the client. Sometimes the interpretive work can be better heard and integrated in a later session. With the growth of trust and ability to integrate, the time lag may be shortened. This was clear with CG. Particularly when transference work involving his behavior towards me was involved, he frequently found it 
The Case of "CG": Balancing Supportive and Insight-Oriented,

Psychodynamic Therapy with a Client Undergoing Intense Life Stresses

K.R. Skean

Pragmatic Case Studies in Psychotherapy, http://pcsp.libraries.rutgers.edu

Volume 1, Module 3, Article 1, pp. 1-18, 10-21-05 [copyright by author]

easier to process some affects after the fact. His early mistrust of me, for example, was something we continued to refer back to. The first form in which we dealt with it was the fear of my abusing him, as in the fantasies of my betrayal of confidentiality, somehow telling his department that they were right about him and should get rid of him. Later in the therapy he acknowledged that there had been an equally strong fear of rejection. When I asked what form this might take, he said one like he experienced with his father, being ignored, treated as an inanimate object, as if he were not there. Some of his stereotypes of therapy - the impassive "uhhuh" or the silent and indifferent therapist - fit into that. Thus, he feared from me both sides of his father's treatment of him, the indifference and the abuse, both the "frightening emptiness" and the "frightening persecution" (Guntrip, 1965). CG clearly would not have been able to articulate all these things in that initial period when these feelings were at their keenest.

\section{A Struggle to Survive: Supportive Psychotherapy (Session 13 to 23)}

Throughout the year, therapy walked a tightrope between times when survival itself seemed the issue for $\mathrm{CG}$ and quieter times when he could engage in psychological work with greater freedom from external stress. Though these "external" stresses were certainly partly of his own making, they nevertheless had a life of their own and impinged upon his current reality. By early October, once the semester was in full gear, therapy shifted into a more supportive mode, as CG began to feel more and more overwhelmed. He struggled with statistics courses (the program prerequisites he had failed the previous year) that truly were more difficult than he could handle, studying almost round the clock and coming in almost incoherent from exhaustion yet unable to even think of the possibility of quitting.

\section{Oasis (Session 24 to 28)}

The break between semesters, from Mid-December to mid-January was a kind of oasis, both for him and for the therapy, one of the few breaks in what was felt as the steady pressure to perform and produce in a hostile environment. CG was able to use this time to venture into new territory, to return to a time when he was able to both try out some new behaviors and to be more reflective once again about our therapeutic relationship, that is, to use transference enactments as a vehicle for learning rather than the needing to use the relationship primarily as a holding environment to survive a dark time (which was a very appropriate use of it in the previous two to three months). The following vignette illustrates the power of the supportive function of therapy, the provision of a kind of parenting experience CG had been denied; and the opportunity this experience provided for insight. In this instance, it involved interest in and encouragement of the client's trying out a very new kind of behavior about which he was quite shaky and unsure of himself. During Winter Break, he took the unprecedented step of not only going into New York for pleasure, but of asking a woman for a date. He had known L slightly while growing up (their sisters had been friends). Knowing she was working in New York, he got her phone number, called her and arranged to meet for brunch. This worked out better than he anticipated; he enjoyed himself and spent much of the afternoon talking with her. 
The Case of "CG": Balancing Supportive and Insight-Oriented,

Psychodynamic Therapy with a Client Undergoing Intense Life Stresses

K.R. Skean

Pragmatic Case Studies in Psychotherapy, http://pcsp.libraries.rutgers.edu

Volume 1, Module 3, Article 1, pp. 1-18, 10-21-05 [copyright by author]

There was a mixture of feelings in presenting the story of his date to me - the excitement and pleasure of a child bringing an accomplishment home, but an undercurrent of anxiety as well. I asked how it was to tell me of this. CG said that part of him somehow felt that I would disapprove and think that he should have been home working, should not have spent the money or the time on pleasing himself. Yet, he went on, now that he said this he realized that was not how I felt at all, that I seemed pleased that he had done it. At this point, he began to cry and said that he just realized there had never been anyone in his life who gave him a feeling that he should be happy, should do things that brought him pleasure. This is important not only in showing the client's ability to allow himself a different kind of experience with another person, but also shows the beginnings of an ability to sort out his projections from the reality of a situation. As an intervention, this was a combination of support and insight, in that the support for his pleasurable strivings allowed the client himself to have the insight that his lived experience of me differed from his projections of my disapproval.

\section{Termination from the Client's Academic Program: A Death Blow to an Old Self (Sessions 29 to36)}

The oasis ended abruptly when CG learned from the faculty at the beginning of the spring semester that he was being dismissed from his program, his most feared outcome. When he received notification of his dismissal, he immediately began an appeals process through which there was an agreement that he was allowed to finish the spring semester, but would then have to leave.

As these stresses mounted, CG's functioning by February of that academic year seemed to be quite impaired. He was rigidly fixed on working every possible moment, even though he was so exhausted and sleep-deprived that his work suffered. He was not eating well and began to have a number of somatic complaints - stomach pains, heart pains - that the health center diagnosed as stress-related. Concentration was so impaired that he would sometimes lose his train of thought in the middle of a sentence while speaking to me. Using the trust that had been developed within the therapeutic relationship up to that point, I urged CG to see a psychiatrist for a consultation; and although he was initially reluctant, he then did agree. He was seen promptly by a psychiatrist at the university, who told me that she would have prescribed antidepressant medication, but that $\mathrm{CG}$ was reluctant to consider it. She recommended that psychotherapy proceed, with the option of revisiting the medication possibility if the situation worsened.

It seemed quite clear that the final rejection from CG's program dealt a death blow to his brittle sense of self, which had been founded upon academic and work achievements, CG's one arena of competence. I worked very directly in this period with this loss of a sense of self and the absence of a basis for a new sense of self. (Kegan, 1982; Wolf, 1988) He responded with considerable affect to this kind of interpretation, dissolving into tears and saying, "That [being an achieving student] is all I've ever been. That's all I've ever had. I don't know who I am anymore." 
The Case of "CG": Balancing Supportive and Insight-Oriented,

Psychodynamic Therapy with a Client Undergoing Intense Life Stresses

K.R. Skean

Pragmatic Case Studies in Psychotherapy, http://pcsp.libraries.rutgers.edu

Volume 1, Module 3, Article 1, pp. 1-18, 10-21-05 [copyright by author]

The mourning of this loss of self seemed to open a wedge for beginning to consider other ways of being. He began to talk about a wish ultimately to marry, to have an intimate relationship, a wish he had always set aside as being impossible or as only possible at some vague future time when everything else in his life was "settled." Emerging from this period of mourning, his rage at his department declined and he began to view the circumstances more as a situation that just hadn't worked out for him for a number of reasons rather than one of malicious persecution. He also began to share slightly more of himself with others, though this was new and anxiety-provoking. Having kept his academic difficulties a tightly guarded secret, he began to share them with a few selected people, and found that their response was sympathetic. The interpersonal world, though far from fully joined and integrated, took on a slightly different aspect. It was no longer monolithically rejecting, but occasionally accessible.

He also showed, over the course of the year, an increasing ability to be curious about his own psychological workings. Again, it remained important to offer interpretations in a tentative way, allowing him to take them in at his own pace, or to carefully link interpretations to other understandings already achieved. For example, it was some six months into treatment before he was able to ask, in a tone of genuine interest and curiosity, "Do you think I could be setting any of this up?" For this patient, I felt it was crucial to let him be the one to state this first. I could then, with shared interest and curiosity, say, "You know, I think you could be on to something there. Let's look at it." At this point, in the context of an environment that had become relatively safe, such an idea could be jointly explored, while earlier, and coming from the therapist, it would have been felt as an intrusive, narcissistic injury. This was followed rapidly by such questionings as, "I was wondering if I'm sort of a rigid person," or "I was reading in one of my management class textbooks about people who have conflicts with authority figures, and I thought some of it fit me."

\section{Termination of the Therapy (Sessions 37 to 42)}

The termination phase of therapy was ushered in by the news of CG's dismissal from his program. Not only would this end his eligibility for services, but he then planned to return to his home state. At first, it seemed he might have to leave immediately, but the appeals process, which resulted in his negotiating being able to stay for the remainder of the semester, earn credits, but not the degree, was finalized towards the end of February. Thus, our ending had a clear date some two and a half months prior to the event. It was acknowledged throughout this period, but dealt with most intensively in the final six weeks of treatment.

CG was surprisingly forthright in dealing with the ending. His ability to personalize and take from the therapy relationship had grown steadily over the year, moving from the early "This session was not helpful" to "This [unspecified 'this'] is helping quite a bit" to "You have become very important to me." Still, the first attempt to deal with the termination was by trying to objectify the relationship, finding out how he could replicate it elsewhere. He asked me how he would go about finding a therapist in his new location, what background and training would be most similar to mine, and could I draw up a treatment plan that he could take with him so that he 
could continue his work in an uninterrupted way. However, as the interest in a new therapist was explored, he was soon able to acknowledge that this was a way of avoiding a very personal separation from me. Yet, as Vaillant (1977) stresses, defenses need to be understood as adaptive, and there was in this reaction a healthy and appropriate side as well, reflecting both CG's historical style of engaging problems by rapidly developing concrete action plans and his emergent ability to believe in the potential of others to be helpful. We did, in fact, make a plan that CG would contact the counseling center of the university he had attended, which was in the city to which he planned to return, and obtain advice on local referrals from them. Meanwhile, the emotional work of our termination continued.

CG said that this was the first time in his life he had ever left anyone that he wished he did not have to leave. His grandmother died after a long illness during our final weeks of treatment, and he stated in the session in which we discussed this that he was more saddened by the parting from me than by his grandmother's death. He felt guilty for feeling this way, but said that, unlike his family relationships, this was the first from which he felt he had gained something.

CG used several revealing metaphors in the termination. He felt in therapy like "a turtle, who had for the first time stuck his head out of his shell." Another metaphor for the accomplishment of his current work - the beginnings of bringing the interpersonal into his world - was that of photographs. In our next to last session, he told of a scrapbook he had kept of his life that he had just been looking through. He noticed for the first time that the scrapbook contained absolutely no pictures of people. It contained things like good report cards, letters of promotion, and some photographs he had taken, but "They were pictures of buildings, occasional scenic pictures, but nothing you couldn't buy on a postcard." He began to think that he wanted some pictures of people from his time here, and had asked a few people he knew if he could take their pictures. He was afraid at first that they would refuse or think him foolish. However, they had responded quite positively. He thus worked his way up to asking if he could take my picture in our last session, acknowledging that this was frightening to him to ask but was something he very much wanted. A little anxious about asking, which he did somewhat shyly and tentatively, he was clearly moved when I agreed. He had found a very appropriate ritual of closure for our last session. The lonely postcard landscape had begun to be populated. He thus in symbolic form (and one hopes also internally) took something of the good parts of the experience with him.

\section{THERAPY MONITORING AND USE OF FEEDBACK INFORMATION}

As mentioned in section 1 above, there was ongoing supervision while the case was in process. This was especially important at the beginning of therapy in helping me to articulate and manage the negative, countertransferential feelings I was having towards the client at the beginning of therapy. If I had allowed these feelings to be expressed, they would have confirmed the client's initial negative expectations of me as another punitive university official and would 
The Case of "CG": Balancing Supportive and Insight-Oriented,

Psychodynamic Therapy with a Client Undergoing Intense Life Stresses

K.R. Skean

Pragmatic Case Studies in Psychotherapy, http://pcsp.libraries.rutgers.edu

Volume 1, Module 3, Article 1, pp. 1-18, 10-21-05 [copyright by author]

have undermined the core, effective process of the therapy, namely, the client's experiencing the therapist as accepting and supportive.

An additional monitoring process took place at the midpoint of treatment. The client was seen by a psychiatrist for a medication consultation. This visit provided outside confirmation of the presence of a moderately severe depression at the midpoint of the treatment following the client's termination from his academic program.

\section{CONCLUDING EVALUATION OF THE THERAPY'S PROCESS AND OUTCOME}

I did not employ standardized, quantitative measures to assess CG's progress. However, there were a variety of clinically important, qualitative changes in CG's behavioral patterns over the course of the therapy that were evidenced in a variety of ways:

- In the therapy, CG was able to reveal for the first time to anyone the story of his very painful and abused childhood. Moreover, he was able to do so with appropriate and deeply felt affect.

- In the therapy, CG came to see a connection between past and present that had previously been denied.

- In the therapy, CG manifested an increasing ability to form a trusting relationship with me. This included his capacity: to share with me his mourning over the loss of our relationship at termination; to share with me his feeling that he had received something very valuable from a human connection; to verbalize how important I was to him; and in the last session to ask for my photograph for his scrapbook.

- Outside the therapy, CG showed the same kind of growth towards meaningful relationships, trying out new kinds of interactions with others: asking a woman for a date, sharing personal concerns with peers at the university, and asking to photograph these peers for his scrapbook. Moreover, as he engaged in this social "outreach," he dealt with the anxiety and confusion this caused without retreating to such "primitive' defenses as emotional constriction and externalization.

- Outside the therapy, CG came through what was a major crisis in his life (failing out of his graduate program), less rather than more entrenched in a bitter and angry view of the world. If crisis represents both danger and opportunity, he was able ultimately to take away some good things from a time in his life which could have threatened only to consolidate older views of an embattled self and hostile others. 
The Case of "CG": Balancing Supportive and Insight-Oriented,

Psychodynamic Therapy with a Client Undergoing Intense Life Stresses

K.R. Skean

Pragmatic Case Studies in Psychotherapy, http://pcsp.libraries.rutgers.edu

Volume 1, Module 3, Article 1, pp. 1-18, 10-21-05 [copyright by author]

It should be noted that the above results might not be unique to a psychodynamic treatment. Any treatment modality that was able to create a safe and containing space for CG could potentially have met many of the treatment goals. However, I believe that the psychodynamic model was particularly helpful in guiding me as the therapist to be in attunement with CG's character style (McWilliams, 1994). Also the model aided me in managing the potentially negative countertransference reactions it provoked, thus helping me to establish a positive therapeutic alliance with the client. For example, my experience of the client as using predominantly paranoid defenses alerted me to the probability that issues of feeling overpowered and humiliated were highly activated. The belief in the importance of the life history suggested to me the possibility that early interactions with caregivers laid down a template for this experience in the present of a simultaneously attacking and uncaring world. The expectation that this would be relived in the therapy relationship through the transference and countertransference helped me see our difficult early sessions as having information value for assessment, treatment and ultimately the forming of a meaningful therapy relationship.

The main lesson for the client of this treatment episode was a simple one: that there is an interpersonal world available that has important experiences to offer. Meissner (1978), following Klein, talks about the move from the paranoid to the depressive position, a developmental move that one can make only when the anxiety of preserving the ego is diminished, and one seeks instead to preserve as "internalized objects" good experiences with others. For this movement to occur, there must be some capacity to identify with good objects. In other words, the primary issue moves from survival to connection.

In the therapy, CG was able to allow himself to experience a different kind of human connection, a connection which allowed him to experience some of the sadness in his life. Cut off from this, he was cut off as well from a whole range of feelings, and with them from the world of interpersonal connectedness. The psychodynamic tradition would by no means see this as a completed therapy. Much work remained to be done. It is clear that CG has an enormous amount of pain and rage still to work through, and a fragile and vulnerable emergent self to nurture. His entry into the interpersonal world is just at its beginning, as is his capacity to allow himself pleasure and joy. Having shown himself to be a person of courage and determination in the difficult work he has thus far done, I hold much hope for his continued growth. For me, the case highlights the potential for a time-limited treatment to provide enough of a holding environment and a different kind of human experience to launch a process that has a promising potential for continued growth, both within therapy and in the outside world. state.

CG left with plans in place to pursue a referral once he was settled again in his home

\section{Follow-Up}

In the final therapy sessions, I could have tried to arrange for continued, follow-up contact with CG. If he had remained in my local area, I would have done this in order to make 
The Case of "CG": Balancing Supportive and Insight-Oriented,

Psychodynamic Therapy with a Client Undergoing Intense Life Stresses

K.R. Skean

Pragmatic Case Studies in Psychotherapy, http://pcsp.libraries.rutgers.edu

Volume 1, Module 3, Article 1, pp. 1-18, 10-21-05 [copyright by author]

available to him the opportunity to return to me for more therapy in the future. Perhaps this would have resulted in seeing CG over time for a number of separate, intermittent episodes, in line with Cummings' (2001) model that is reflected in the title of his recent article, "Interruption, not termination: The model from focused, intermittent psychotherapy throughout the life cycle." And it is true that with some types of clients, I have maintained contact over distance and even at times engaged in ongoing formal phone sessions. However, in terms of the intense, "corrective emotional experience" through which this emotionally and interpersonally constricted individual had undergone during the therapy episode with me, there were theoretical reasons for not maintaining more of a relationship. These reasons include: (1) not wanting to provide just enough of a link that it might have delayed or impeded CG establishing a new therapy relationship after he moved; (2) the idea of continuing contact could have made the termination process less meaningful, rich, and full, since the facing of an ending is one of the elements that gives therapy its power; and (3) the fact that sporadic, follow-up contact outside the frame of therapy is less likely to resemble the therapy, running the risk of retrospectively diminishing the nature and importance of the client's narrative of the original therapy.

On the other hand, it should be noted that from a case study research point of view, it was definitely a loss not to have been able to follow up CG for a considerable time after the termination of our therapy. Perhaps in retrospect, it might have been possible to have CG to agree to have a professional third party keep in touch with him, thus obtaining the follow-up data but not diluting CG's remembered relationship with me.

Because of my decision to not arrange staying in touch with the client, I was not able to contact him for follow-up information. On the other hand, I was recently able to learn through a third party that the client became educationally successful and that today he is in a high level position in his field.

\section{REFERENCES}

Cummings, N.A. (2001). Interruption, not termination: The model from focused, intermittent psychotherapy throughout the life cycle. Journal of Psychotherapy in Independent Practice. 2, 2001, 3-18.

Freud, A. (1966). The ego and the mechanisms of defense. New York: International Universities Press. .

Gill, M. (1982). Analysis of transference (Vol. 1). New York: International Universities Press

Guntrip, H. (1969). Schizoid phenomena, object relations and the self. New York: International Universities Press.

Josephs, L. (1995). Balancing empathy and interpretation: Relational character analysis. Northvale, NJ: Jason Aronson, Inc.

Kegan, R. (1982). The evolving self. Cambridge, MA: Harvard University Press. Luborsky, L. (1984). Principles of psychoanalytic psychotherapy. New York: Basic Books. McWilliams, N. (1999). Psychoanalytic case formulation. New York: Guilford Press. McWilliams, N. (1994). Psychoanalytic diagnosis. New York: Guilford Press. 
McWilliams, N. (2004). Psychoanalytic psychotherapy: A practitioner's guide. New York: Guilford Press.

Meissner, W.W. (1978). The paranoid process. New York: Jason Aronson.

Mitchell, S.A., \& Black, M.J. (1995). Freud and beyond. New York: Basic Books.

Pine, F. (1985). Developmental theory and clinical process. New Haven: Yale University Press. Spence, D.P. (1982). Narrative truth and historical truth: Meaning and interpretation in psychoanalysis. New York: Norton.

Strupp, H.H., \& Binder, J.F. (1984). Psychotherapy in a new key. New York: Basic Books.

Vaillant, G. (1974). Adaptation to life. Boston: Little, Brown and Company.

Vaillant, G. (1993). The wisdom of the ego. Cambridge, MA: Harvard university press.

Wachtel, P.L. (1997). Psychoanalysis, behavior therapy, and the relational world. Washington, DC: American Psychological Association.

Winnicott, D.W. (1965). The maturational processes and the facilitating environment. New York: International Universities Press.

Wolf, E.S. (1988). Treating the self: Elements of clinical self psychology. New York:Guilford Press. 